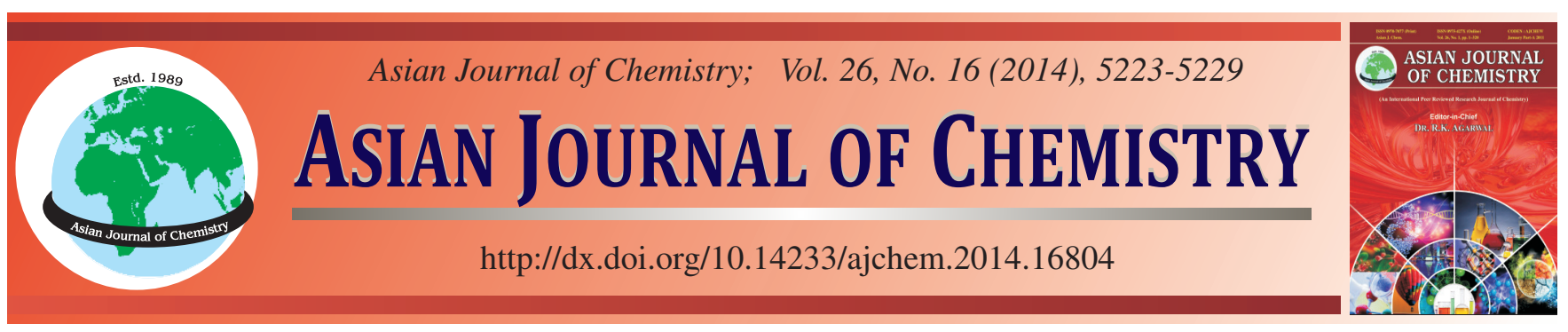

\title{
Comparison of Energy Consumption of Two-Column Configuration and Three-Column Configuration in the Extractive Distillation Process for High Purity Refinement of Isopropyl Alcohol
}

\author{
Xuefei $\mathrm{Wu}^{1}$, Jaehyun Nho ${ }^{2}$, Dong Sun Kim ${ }^{1}$ and Jungho Cho ${ }^{1, *}$
}

${ }^{1}$ Department of Chemical Engineering, Kongju National University, Cheonan, Republic of Korea

${ }^{2}$ Department of Chemical Engineering, Hoseo University, Asan, Republic of Korea

*Corresponding author: Fax: +82 41 5542640; Tel: +82 41 5219366; E-mail: jhcho@kongju.ac.kr

\begin{abstract}
High purity isopropyl alcohol cannot be obtained from an aqueous solution by conventional distillation because isopropyl alcohol in solution will reach an azeotropic point around 68 mole \% (88 wt.\%). However, high purity isopropyl alcohol can be obtained by using ethylene glycol or dimethyl sulfoxide as a solvent in the extractive distillation process, which yields highly purified isopropyl alcohol in the upper part of the distillation column. Herein, the solvent ability of ethylene glycol and dimethyl sulfoxide in the extractive distillation process is compared. In addition, the two-column configuration of the extractive distillation column and solvent recovery column, concentrator, evaporation equipment and the three-column configuration of the extractive distillation column and solvent recovery column are also compared. Computer simulations were conducted for each of the aforementioned processes. Process optimization was also performed for the reduction of utilities cost. The study confirmed that the use of dimethyl sulfoxide as a solvent with application of the three-column distillation configuration was effective for minimizing the consumption of steam.
\end{abstract}

Keywords: Modeling, Simulation, Isopropyl alcohol, Dimethyl sulfoxide, Ethylene glycol, Extraction, Extractive distillation.

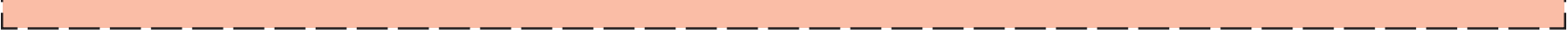

\section{INTRODUCTION}

Production of liquid crystal display (LCD) equipment involves etching of glass substrate and removal of impurities that require a cleaning process after completing the circuitry. High purity isopropyl alcohol (IPA) is used in the cleaning process, thus generating a large amount of isopropyl alcohol wastewater. At present, it is estimated that the isopropyl alcohol wastewater generated in the production of LCDs reaches 1,500 tons per day. The mass ratio of water to isopropyl alcohol in this waste is $43: 57$ on average.

Currently, the generated isopropyl alcohol wastewater is either disposed or simply used as fuel in LCD production companies, not because of its high fuel value. It is a passive alternative to the recycling plan given that above $68 \mathrm{~mol} \%$ isopropyl alcohol cannot be obtained from the mixture of water and isopropyl alcohol in the normal distillation process owing to formation of an azeotrope. Based on Fig. 1, the binary mixture of isopropyl alcohol and water will reach the azeotropic point when the molar fraction of isopropyl alcohol is 0.68 at $101.3 \mathrm{kPa}$.

Besides using the large amount of isopropyl alcohol waste water as a fuel, it can be recycled to regenerate high purity isopropyl alcohol by refining the expensive isopropyl alcohol component and resulting to a significant economic impact. Therefore, this study presents a modeling of the production process for high purity isopropyl alcohol based on the commercial chemical process simulator, PRO/II with PROVISION Version 9.2. The most effective extractive solvent is determined based on comparison of the solvent ability of dimethyl sulfoxide (DMSO) and ethylene glycol (EG). Because DMSO and ethylene glycol are hygroscopic liquids, their affinity for water is very high and their normal boiling points are above $190^{\circ} \mathrm{C}$. Consequently, these extractive solvents can lower the volatility of water by mixing it with the feed of the extractive distillation column. Accordingly, the increase in the relative volatility of water versus isopropyl alcohol in the extractive distillation column enables the refinement of high purity isopropyl alcohol.

\section{THEORETICAL CONSIDERATIONS}

In the process design, the selection of proper thermodynamic models and accurate model parameters is very important. Because the nonideality of the binary mixture of isopropyl alcohol and water is very high in the liquid state, an azeotrope is formed. It is established that the calculation of the vaporliquid equilibria of mixtures with high nonideality in the liquid state should be conducted by using liquid activity coefficient models such as NRTL, UNIQUAC and Wilson ${ }^{2-4}$. In contrast, 


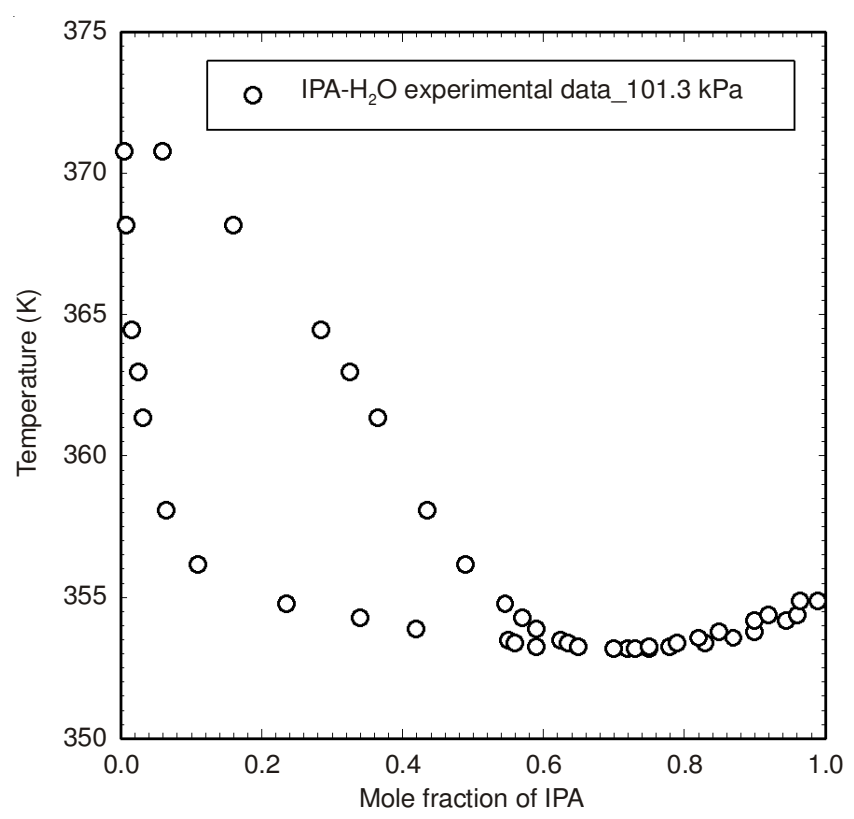

Fig. 1. VLE experimental data (TXY Plot) for the binary system of isopropyl alcohol and $\mathrm{H}_{2} \mathrm{O}$ at $101.3 \mathrm{kPa}$ [Ref. 8]

it is known that the equation of state model Redlich-Kwong (RK) that is transformed by Peng-Robinson (PR) or Soave is appropriate for calculation of the vapor-liquid equilibria of hydrocarbons under high pressure ${ }^{5-7}$. In this study, the NRTL model was adopted in order to estimate the nonideality of the liquid isopropyl alcohol and water mixture. The NRTL liquid activity coefficient model requires three basic binary interaction parameters for each binary system. If the parameters that show the temperature dependence are added, five binary interaction parameters are required. The NRTL liquid activity coefficient model used in this study is shown in equations (1) to (3).

$$
\begin{gathered}
\text { In } \gamma_{\mathrm{i}}=\frac{\sum_{\mathrm{j}} \tau_{\mathrm{ji}} \mathrm{G}_{\mathrm{ji}} \mathrm{x}_{\mathrm{j}}}{\sum_{\mathrm{k}} \mathrm{G}_{\mathrm{ki}} \mathrm{x}_{\mathrm{k}}}+\sum_{\mathrm{j}}+\frac{\mathrm{x}_{\mathrm{j}} \mathrm{G}_{\mathrm{ij}}}{\sum_{\mathrm{k}} \mathrm{G}_{\mathrm{kj}} \mathrm{x}_{\mathrm{k}}}\left(\tau_{\mathrm{ij}}-\frac{\sum_{\mathrm{k}} \mathrm{x}_{\mathrm{k}} \tau_{\mathrm{kj}} \mathrm{G}_{\mathrm{kj}}}{\sum_{\mathrm{k}} \mathrm{G}_{\mathrm{kj}} \mathrm{x}_{\mathrm{k}}}\right) \\
\tau_{\mathrm{ij}}=\mathrm{a}_{\mathrm{ij}}+\frac{\mathrm{b}_{\mathrm{ij}}}{\mathrm{T}} \\
\mathrm{G}_{\mathrm{ij}}=\exp \left(-\alpha_{\mathrm{ij}} \tau_{\mathrm{ij}}\right)
\end{gathered}
$$

Furthermore, Table- 1 shows the NRTL binary interaction parameters of isopropyl alcohol, water, DMSO and ethylene glycol which are built in the PRO/II with PROVISION Version 9.2. In order to confirm the reliability of the process simulation which uses the NRTL model and the NRTL binary interaction parameters, comparative analysis from literature review ${ }^{1,7-10}$ and the test results were utilized. Fig. 2 shows the comparison of the equilibrium test results and calculation results for the binary system of isopropyl alcohol and ethylene glycol at $101.33 \mathrm{kPa}$. Comparison of the equilibrium test results and the calculation results for the binary systems are shown as follows: isopropyl alcohol and DMSO at $6.67 \mathrm{kPa}$ (Fig. 4); water and DMSO at $20 \mathrm{kPa}$ (Fig. 5); water and ethylene glycol at $13.33 \mathrm{kPa}$ (Fig. 6). Based on Figs. 2 to 6, it can be deduced that the NRTL modification and the given binary interaction parameters produce similar calculation results in the normal pressure test and decompression test.

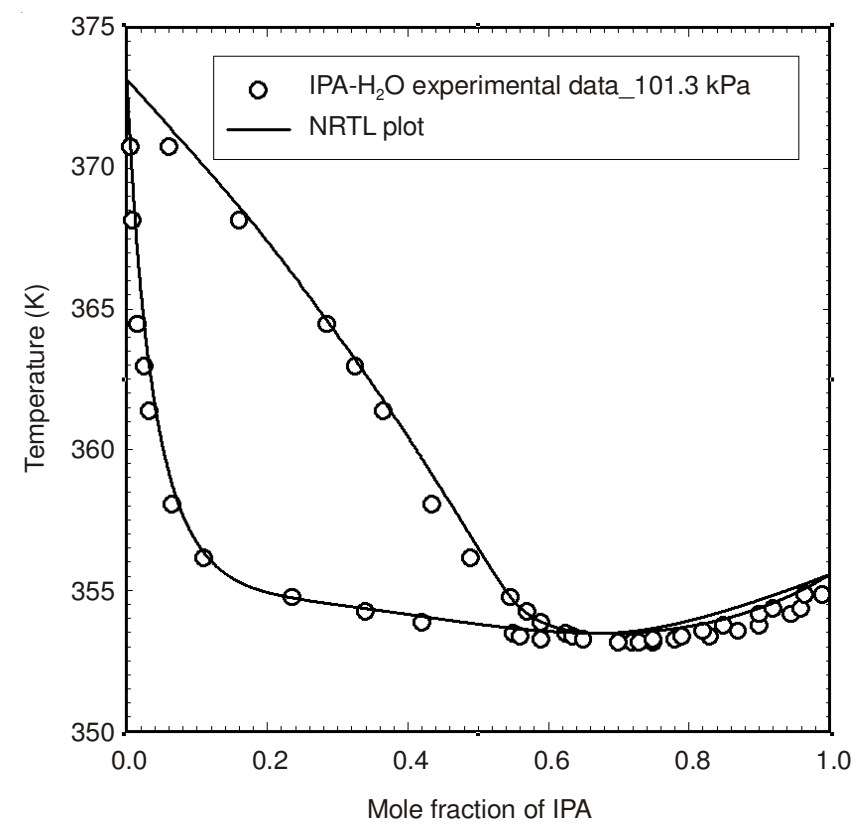

Fig. 2. Comparison between the VLE experimental results and the calculation results for the binary system of isopropyl alcohol and $\mathrm{H}_{2} \mathrm{O}$ at $101.33 \mathrm{kPa}$ isopropyl alcohol [Ref. 1]

\section{RESULTS AND DISCUSSION}

Extractive distillation process: A two-column distillation configuration or a three-column distillation configuration may

\begin{tabular}{|c|c|c|c|c|c|c|}
\hline $\mathrm{i}$ & $\mathrm{j}$ & $\begin{array}{l}\mathrm{a}_{\mathrm{ij}} \\
\mathrm{a}_{\mathrm{ji}}\end{array}$ & $\begin{array}{l}b_{i j} \\
b_{j i}\end{array}$ & $\begin{array}{l}c_{i j} \\
c_{j i}\end{array}$ & $\alpha_{i j}$ & Units \\
\hline \multirow{2}{*}{ IPA } & \multirow{2}{*}{$\mathrm{H}_{2} \mathrm{O}$} & 0.753 & -267.132 & 0 & \multirow{2}{*}{0.3111} & \multirow{2}{*}{ K } \\
\hline & & 1.059 & 461.719 & 0 & & \\
\hline \multirow{2}{*}{ IPA } & \multirow{2}{*}{ DMSO } & 0.000 & 697.088 & 0 & \multirow{2}{*}{0.3000} & \multirow{2}{*}{ K } \\
\hline & & 0.000 & -305.335 & 0 & & \\
\hline \multirow{2}{*}{ IPA } & \multirow{2}{*}{ EG } & 0.000 & -751.991 & 0 & \multirow{2}{*}{0.0467} & \multirow{2}{*}{$\mathrm{K}$} \\
\hline & & 0.000 & 1158.580 & 0 & & \\
\hline \multirow{2}{*}{$\mathrm{H}_{2} \mathrm{O}$} & \multirow{2}{*}{ DMSO } & 0.000 & 1203.770 & 0 & \multirow{2}{*}{0.6615} & \multirow{2}{*}{$\mathrm{K}$} \\
\hline & & 0.000 & -524.821 & 0 & & \\
\hline \multirow{2}{*}{$\mathrm{H}_{2} \mathrm{O}$} & \multirow{2}{*}{ EG } & 0.000 & 1888.750 & 0 & \multirow{2}{*}{0.0773} & \multirow{2}{*}{ K } \\
\hline & & 0.000 & -1445.470 & 0 & & \\
\hline \multirow{2}{*}{ DMSO } & \multirow{2}{*}{ EG } & 0.000 & 429.425 & 0 & \multirow{2}{*}{0.3024} & \multirow{2}{*}{ K } \\
\hline & & 0.000 & -635.761 & 0 & & \\
\hline
\end{tabular}

TABLE-1

NRTL BINARY INTERACTION PARAMETERS FOR PAIRS AMONG ISOPROPYL ALCOHOL, $\mathrm{H}_{2} \mathrm{O}$, DMSO AND ETHYLENE GLYCOL 


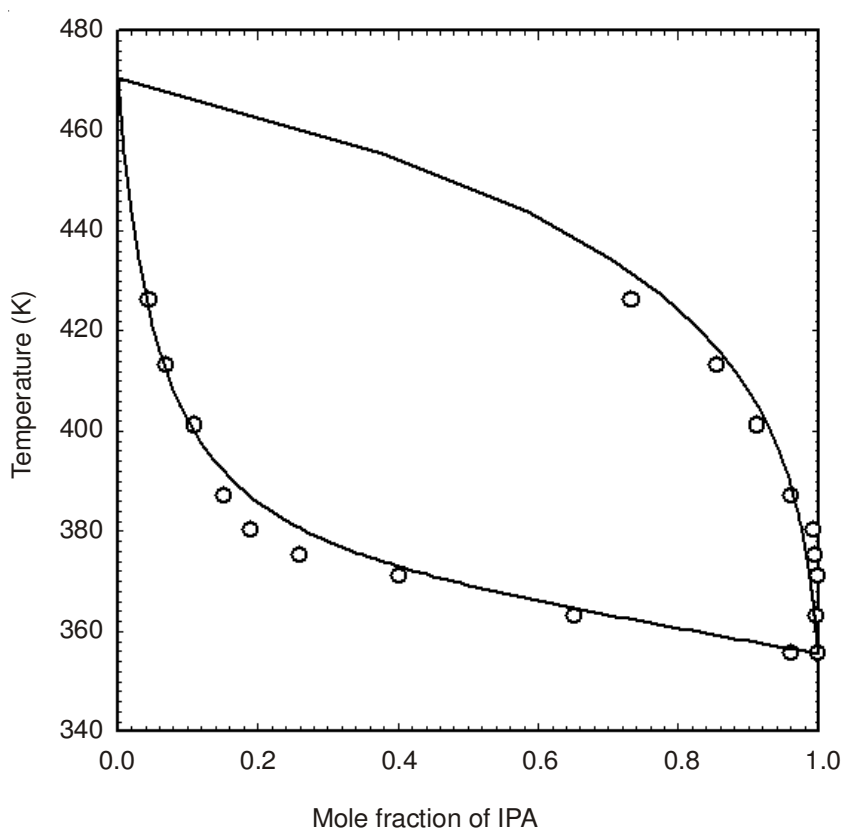

Fig. 3. Comparison between the VLE experimental results and the calculation results for the binary system of isopropyl alcohol and ethylene glycol at $101.33 \mathrm{kPa}$ [Ref. 7]

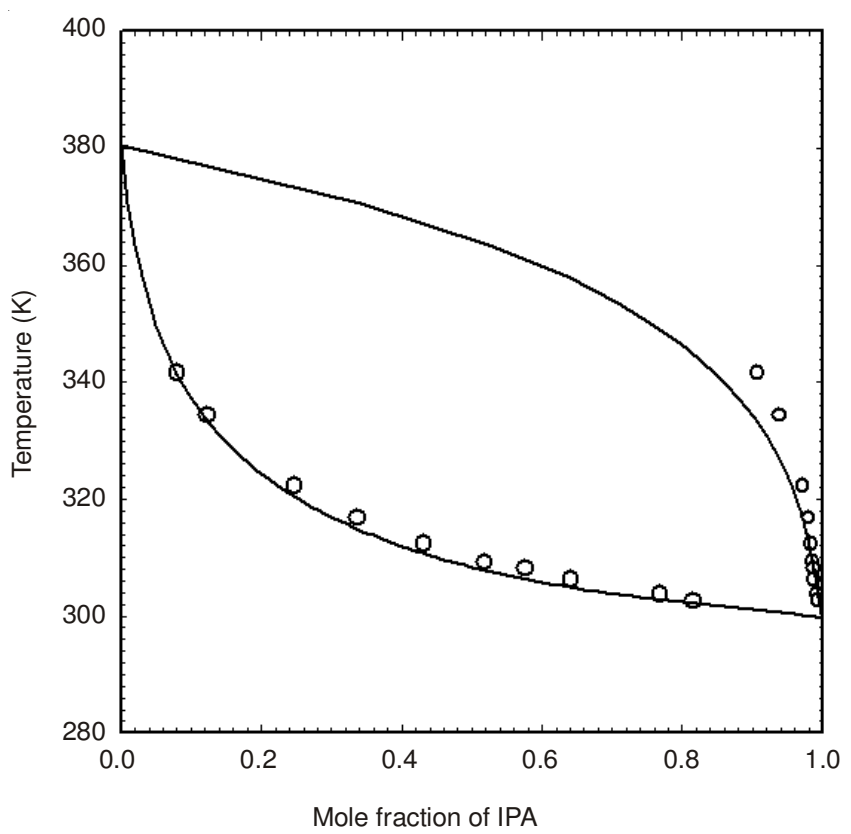

Fig. 4. Comparison between the VLE experimental results and the calculation results for the binary system of isopropyl alcohol and DMSO at $6.67 \mathrm{kPa}$ [Ref. 8]

be used to produce high purity isopropyl alcohol by recycling in the extractive distillation process as shown in Figs. 7 and 8. The difference between these two configurations lies in whether or not a concentrator is used. That is, in the case of the three-column distillation configuration, the concentrator is used in the front end of the extractive distillation columns and the isopropyl alcohol wastewater will be condensed before the azeotropic point. With the use of the concentrator, the operational costs of the process can be reduced given that much of the water is removed by the concentrator. Moreover, the purpose of the extractive distillation column is to obtain mostly purified isopropyl alcohol from the upper part of the column

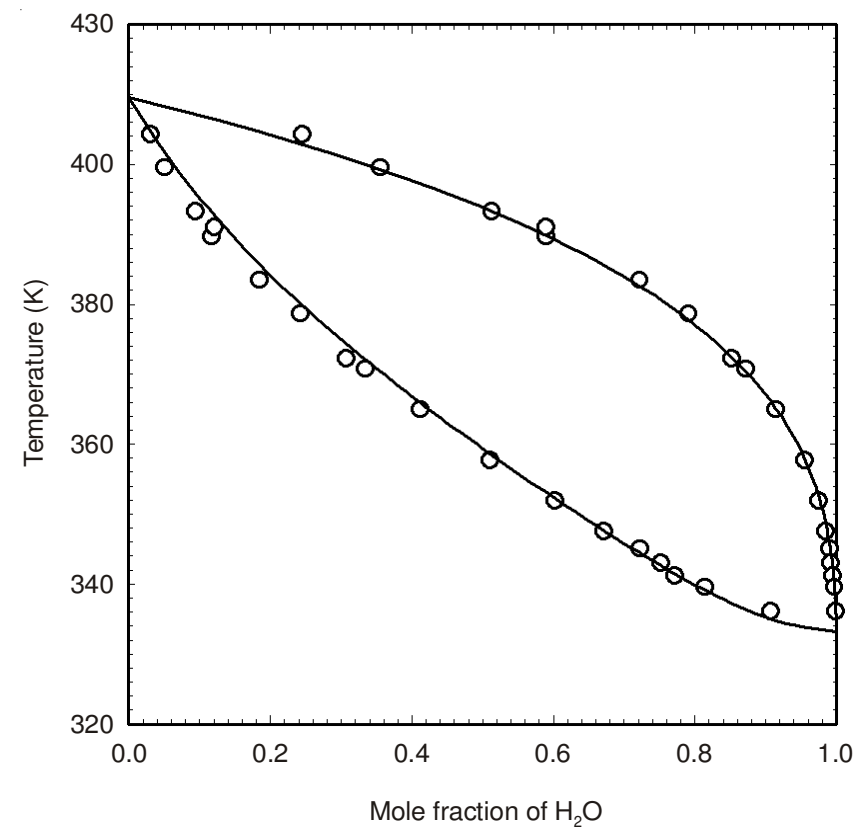

Fig. 5. Comparison between the VLE experimental results and the calculation results for the binary system of $\mathrm{H}_{2} \mathrm{O}$ and DMSO at $20.00 \mathrm{kPa}$ [Ref. 9]

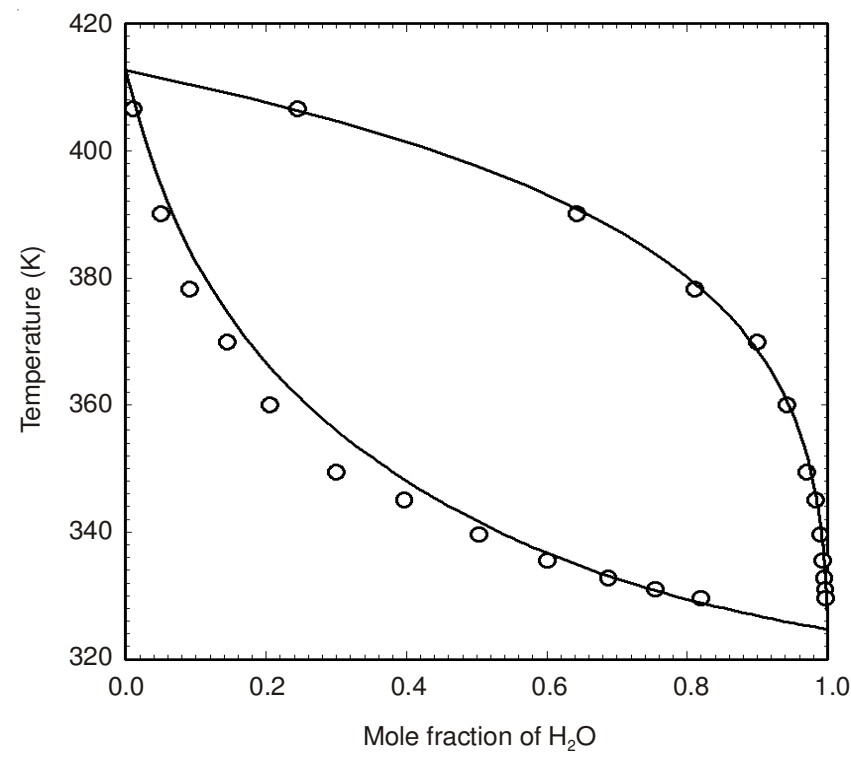

Fig. 6. Comparison between the VLE experimental results and the calculation results for the binary system of $\mathrm{H}_{2} \mathrm{O}$ and ethylene glycol at 13.33 $\mathrm{kPa}$ [Ref. 10]

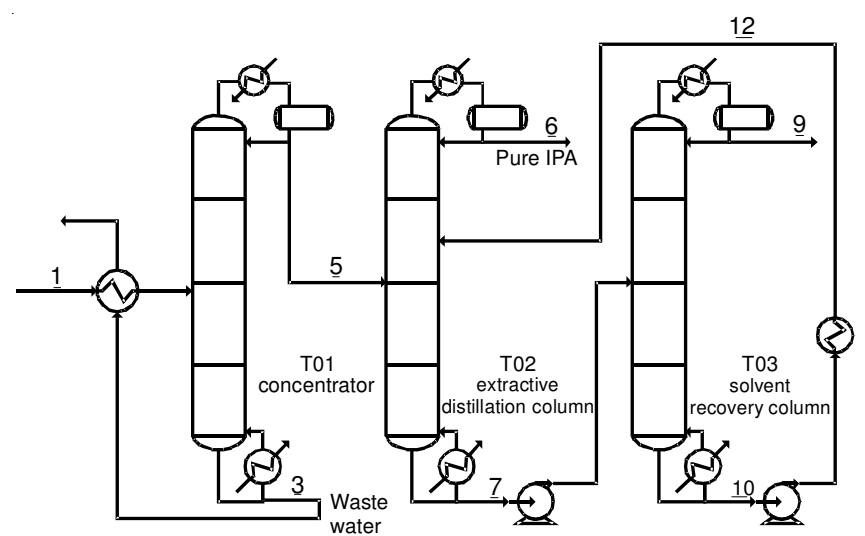

Fig. 7. A schematic representation of an extractive distillation having 2 column configuration for high-purity refining of isopropyl alcohol (IPA) using DMSO or ethylene glycol as an extractive solvent 


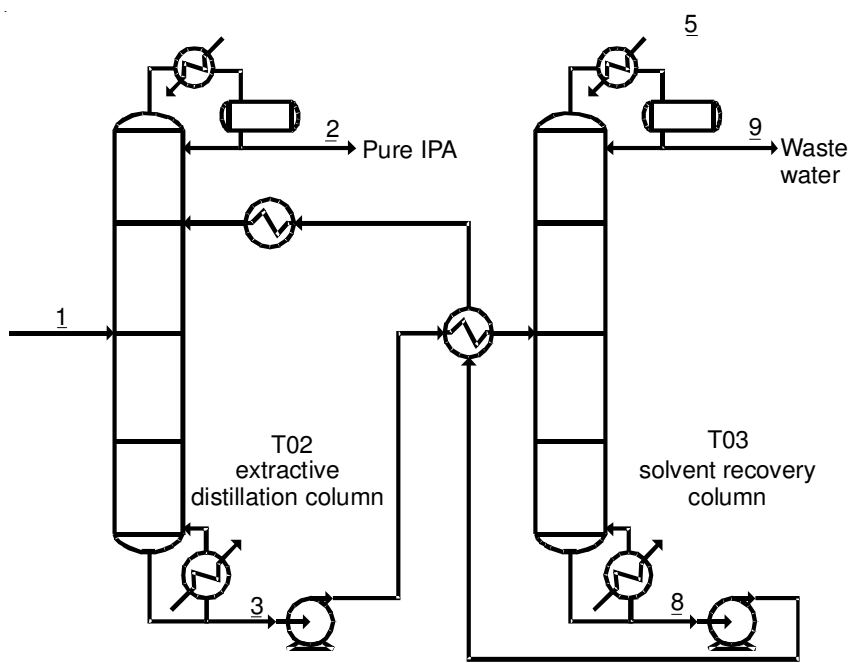

Fig. 8. A schematic representation of an extractive distillation process having 3 column configuration for high-purity refining of IPA using DMSO or EG as an extractive solvent

with the use of extractive solvents. A mixture containing water, extractive solvents and a very small amount of isopropyl alcohol will be discharged from the lower part of the extractive distillation column. This mixture is then sent to the solvent recovery column. The solvent recovery column facilitates reuse of the solvents (as extractive solvents) for the extractive distillation column by collecting them from the mixture in the lower part of the column. The components and composition of the raw materials were those of the isopropyl alcohol waste water obtained from domestic semiconductor enterprises as shown in Table-2.

TABLE-2

ISOPROPYL ALCOHOL COMPONENTS AND THEIR COMPO-

SITIONS IN THE ISOPROPYL ALCOHOL WASTE SOLUTION

\begin{tabular}{cc}
\hline Component & Mass $(\%)$ \\
\hline Isoproply alcohol & 57.2 \\
Water & 42.8 \\
Temperature $(\mathrm{K})$ & 50.0 \\
Pressure $(\mathrm{kPa})$ & 250 \\
Flow rate $(\mathrm{kg} / \mathrm{h})$ & $3,000.0$ \\
\hline
\end{tabular}

Concentrator simulation: Concentrator condenses the isopropyl alcohol in the lower part of the column before the azeotropic point and decreases the isopropyl alcohol content in the wastewater from the column at less than $500 \mathrm{ppm}$. Herein, the theoretical plate number used for the concentrate was 25. Fig. 9 shows that the mass composition of isopropyl alcohol in the wastewater from the lower part of the concentrator column satisfied the $500 \mathrm{ppm}$ limit. It also shows the heat duty of the concentrator reboiler based on the isopropyl alcohol purity of the overhead products. From the results, it can be deduced that the heat duty of the concentrator reboiler increased when the isopropyl alcohol purity of the overhead products was $87.3 \mathrm{wt} . \%$.

Extractive distillation column simulation: Extractive distillation column is utilized to refine pure isopropyl alcohol from the overhead products with the use of the extractive solvent. The extractive solvent that is selectively mixed with the water in the raw materials from the extractive distillation column will be discharged from the lower part of the column.

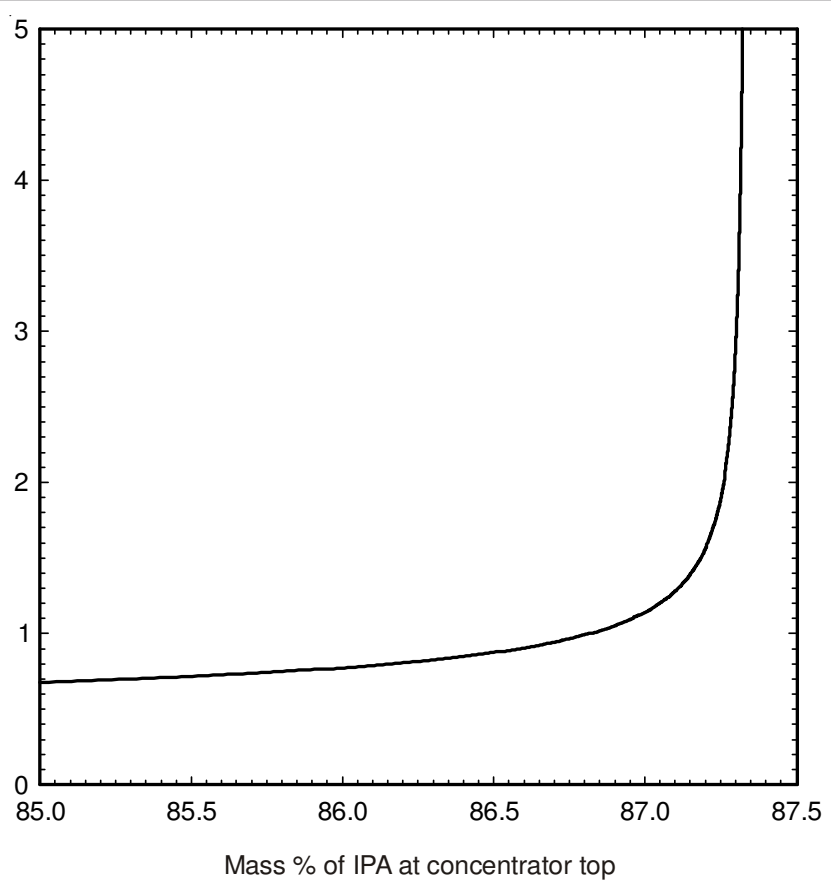

Fig. 9. Reboiler heat duty according to the purity of isopropyl alcohol in the top side product of the concentrator

The process was simulated with the objective to lower the water content of the isopropyl alcohol products to less than $1 \mathrm{ppm}$ and to reduce the isopropyl alcohol in the mixture discharged from the extractive distillation column to less than $50 \mathrm{ppm}$ by refining the isopropyl alcohol to $99.7 \mathrm{wt}$.\% on the upper part of the column.

Solvent recovery column simulation: Purpose of the solvent recovery column is to refine the extractive solvent from the mixture that is discharged from the extractive distillation column to facilitate reuse of the solvent.

The process was simulated herein with the objective of lowering the water content of the extractive solvent to 100 ppm and to reduce the isopropyl alcohol from the wastewater that is discharged from the upper part of the column (such as the concentrator) to less than $500 \mathrm{ppm}$. In order to achieve this purpose, the necessary theoretical plate number for the removal column was set at 25 . In addition, the operational pressure in the solvent recovery column reboiling process was determined in order to utilize the MP steam $\left(180^{\circ} \mathrm{C}\right.$ saturated steam) and increase the reboiler temperature to $160{ }^{\circ} \mathrm{C}$.

\section{Comparison between DMSO and ethylene glycol solvents}

Two-column configuration process: Table- 3 shows the circulation flow of the extractive solvent for determination of the total reboiler heat duty recovery of isopropyl alcohol with 99.7 wt.\% purity using ethylene glycol and DMSO as the extractive solvents in the two-column configuration without a concentrator. The rate of ethylene glycol solvent inflow for the recovery of isopropyl alcohol with $99.7 \mathrm{wt} . \%$ purity was $6,765 \mathrm{~kg} / \mathrm{h}$ and the total steam consumption required for this process was around 7,567 kg/h. On the other hand, the rate of solvent inflow of DMSO for the recovery of isopropyl alcohol with 99.7 wt.\% purity was $4,397 \mathrm{~kg} / \mathrm{h}$ and the total steam consumption of the process was $7,131 \mathrm{~kg} / \mathrm{h}$. Overall, compared to the use of ethylene glycol, the use of DMSO as the extractive 


\begin{tabular}{|c|c|c|}
\hline \multicolumn{3}{|c|}{$\begin{array}{l}\text { TABLE-3 } \\
\text { SIMULATION RESULTS OF THE } 2 \text { COLUMN CONFIGURATION } \\
\text { WHEN EG OR DMSO IS USED AS AN EXTRACTION SOLVENT }\end{array}$} \\
\hline Items & $\begin{array}{c}\text { Two-columns } \\
\text { (EG) }\end{array}$ & $\begin{array}{c}\text { Two-columns } \\
\text { (DMSO) }\end{array}$ \\
\hline Condenser duty of T02 (kcal/h) & $0.9655 \times 10^{6}$ & $0.9655 \times 10^{6}$ \\
\hline Condenser duty of T03 (kcal/h) & $2.1816 \times 10^{6}$ & $2.2018 \times 10^{6}$ \\
\hline Total condenser duty $(\mathrm{kcal} / \mathrm{h})$ & $3.1471 \times 10^{6}$ & $3.1673 \times 10^{6}$ \\
\hline Reboiler duty of $\mathrm{T} 02(\mathrm{kcal} / \mathrm{h})$ & $1.5645 \times 10^{6}$ & $1.3303 \times 10^{6}$ \\
\hline Reboiler duty of T03 (kcal/h) & $2.0777 \times 10^{6}$ & $2.1020 \times 10^{6}$ \\
\hline Total reboiler duty (kcal/h) & $3.6422 \times 10^{6}$ & $3.4323 \times 10^{6}$ \\
\hline Solvent circulation rate $(\mathrm{kg} / \mathrm{h})$ & 6,765 & 4,397 \\
\hline C/W consumption (ton/h) & 393 & 396 \\
\hline MP steam consumption $(\mathrm{kg} / \mathrm{h})$ & 7,567 & 7,131 \\
\hline
\end{tabular}

solvent for the refinement of isopropyl alcohol with $99.7 \mathrm{wt} \%$ purity reduced the required solvent inflow rate by $35 \%$ and decreased the total steam consumption by $5.8 \%$.

Three-column configuration process: In the three-column distillation setup, the concentrator is added to the extractive distillation column of the two-column distillation setup. Fig. 10 shows the reboiler heat duty of the concentrator, extractive distillation column and solvent recovery column based on the isopropyl alcohol purity on the overhead products in the concentrator when ethylene glycol was used as the extractive solvent. Fig. 11 shows the reboiler heat duty when DMSO was used as the extractive solvent.

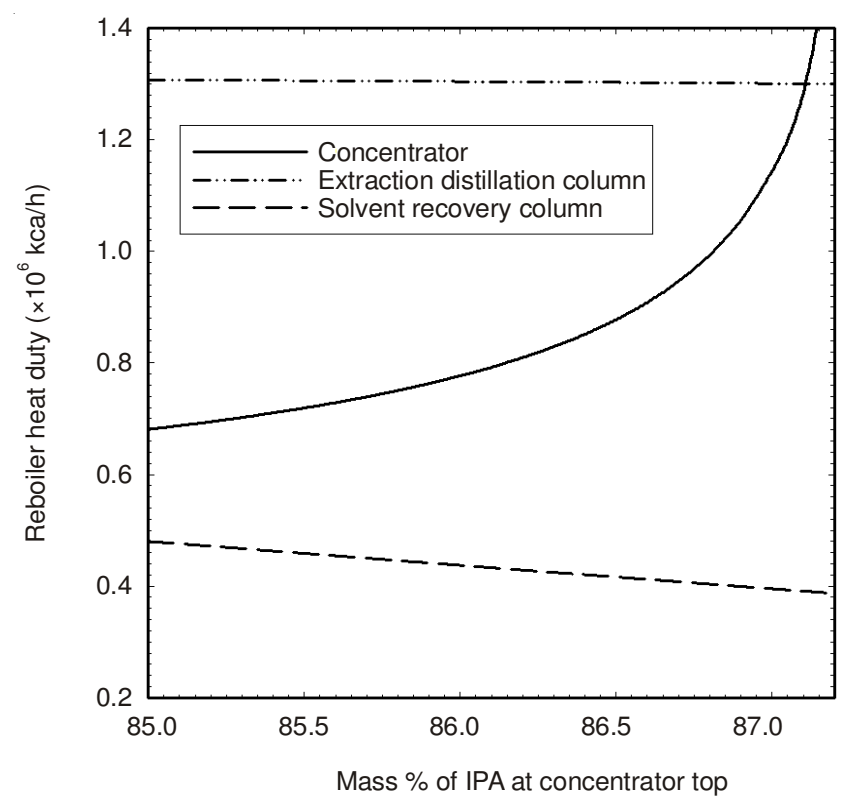

Fig. 10. Reboiler heat duty in the concentrator, extractive distillation column and stripper according to the purity of IPA in the top side product of the concentrator (when EG is used as an extractive solvent)

Figs. 10 and 11 show that as the isopropyl alcohol purity of the overhead products in the concentrator increases, the reboiler heat duty of the extractive distillation column and solvent recovery column decreases due to a decline in water content in the raw materials discharged from the extractive distillation column owing to concentration and lowering of the required extractive solvent inflow rate. However, as the

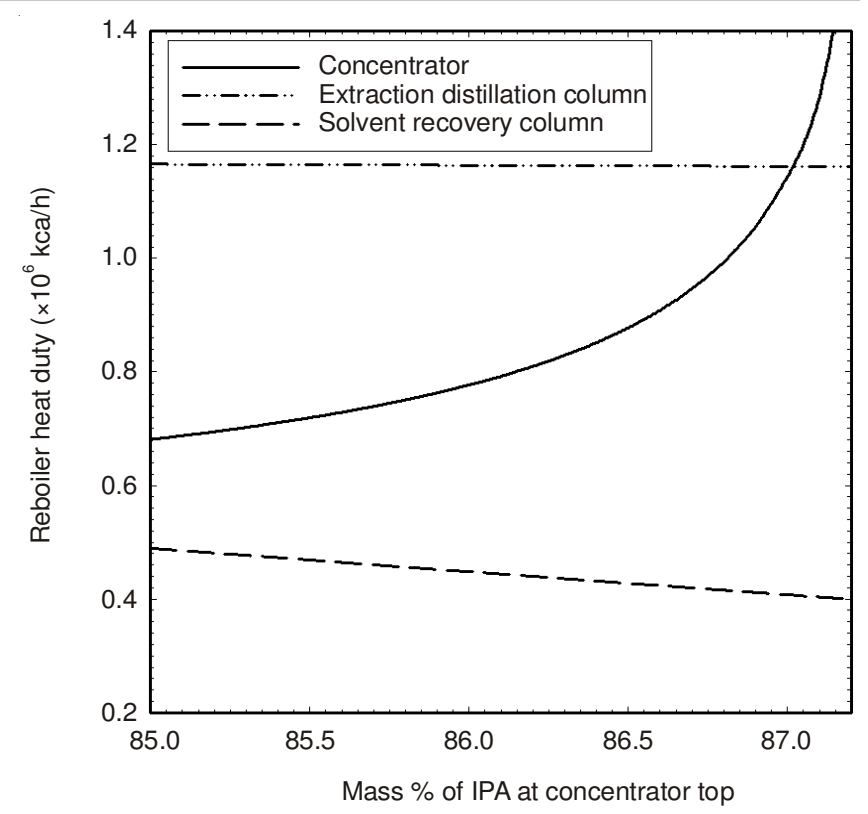

Fig. 11. Reboiler heat duty in the concentrator, extractive distillation column and stripper according to the purity of IPA in the top side product of the concentrator (when DMSO is used as an extractive solvent)

reboiler heat duty of the concentrator increases, there will be a minimum point of the total reboiler heat duty of the threecolumn distillation setup. Accordingly, Figs. 12 and 13 show the reboiler heat duty of the three-column distillation setup on the basis of the isopropyl alcohol purity of the overhead products in the concentrator when ethylene glycol and DMSO were respectively used as the extractive solvent. When ethylene glycol was used as the extractive solvent and the purity of isopropyl alcohol in the concentrator was $84.5 \mathrm{wt} . \%$, the total reboiler heat duty of the three-column distillation setup was

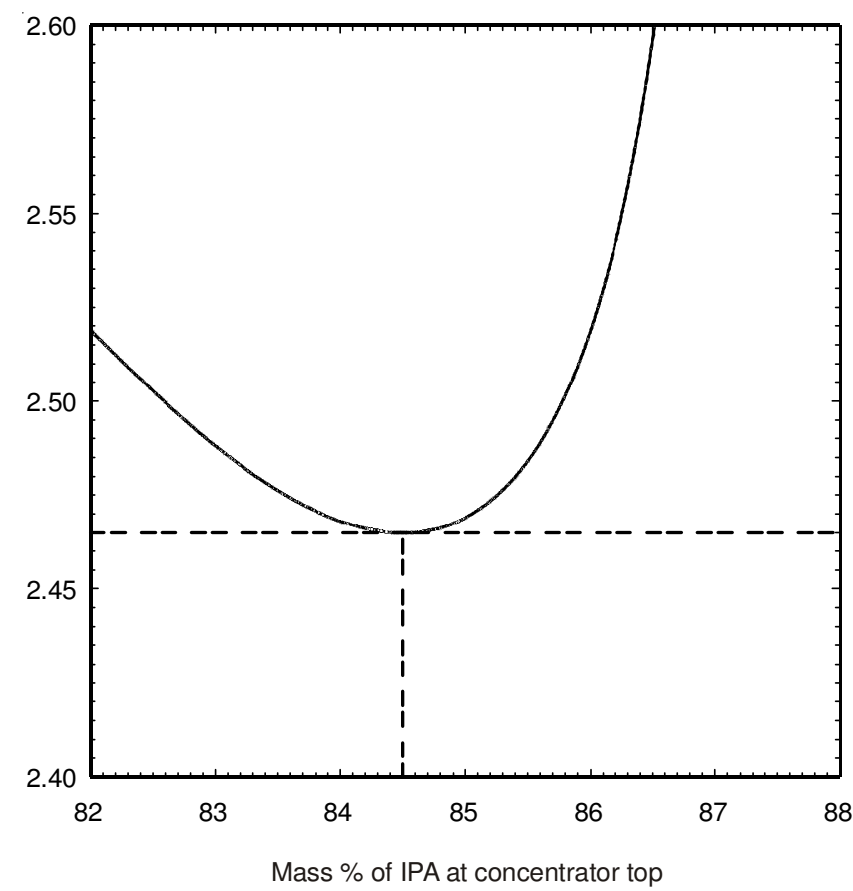

Fig. 12. Sum of reboiler heat duties in the concentrator, extractive distillation column and stripper according to the purity of isopropyl alcohol in the top side product of the concentrator (when EG is used as an extractive solvent) 


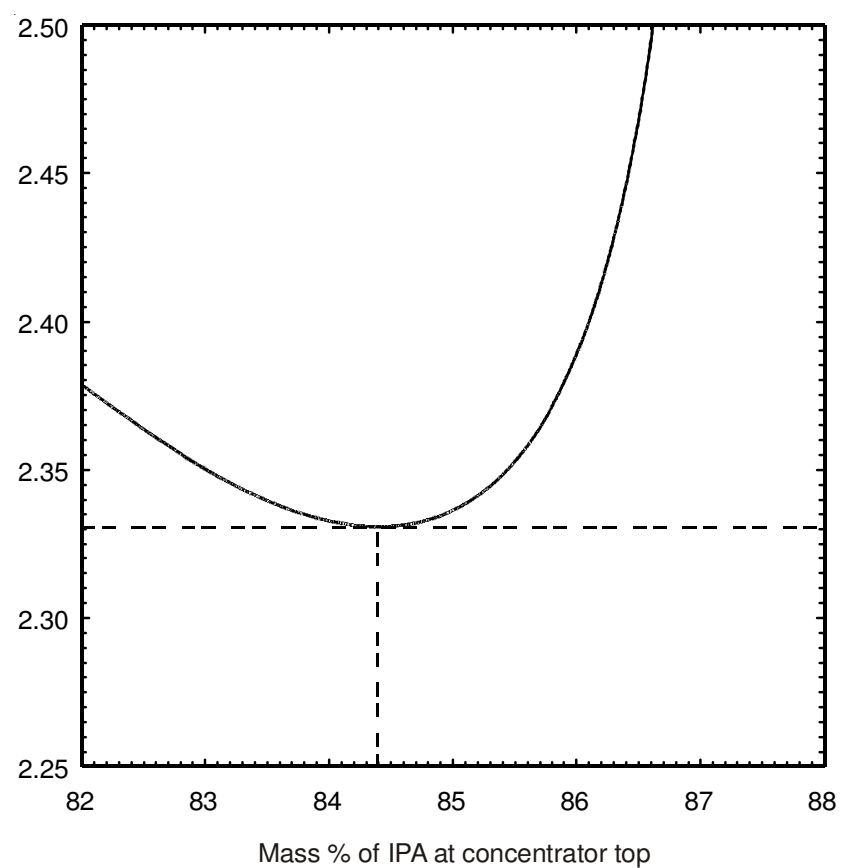

Fig. 13. Sum of reboiler heat duties in the concentrator, extractive distillation column and stripper according to the purity of isopropyl alcohol in the top side product of the concentrator (when DMSO is used as an extractive solvent)

$2.4648 \times 10^{6} \mathrm{kcal} / \mathrm{h}$ which reached the minimum. When DMSO was used as the extractive solvent and the purity of isopropyl alcohol in the concentrator was $84.5 \mathrm{wt}$. \%, the minimum total reboiler heat duty reached $2.3310 \times 10^{6} \mathrm{kcal} / \mathrm{h}$.

Table- 4 shows the inflow rate of the extractive solvent for determination of the total reboiler heat duty and recovery of isopropyl alcohol with $99.7 \mathrm{wt} \%$ purity when ethylene glycol or DMSO is used as the extractive solvent in the threecolumn configuration with the concentrator. The solvent inflow rate of ethylene glycol for recovery of isopropyl alcohol with 99.7 wt. $\%$ was about $4,017 \mathrm{~kg} / \mathrm{h}$ and the total steam consumption required for the process was about $5,035 \mathrm{~kg} / \mathrm{h}$. The solvent inflow rate of DMSO for the recovery of isopropyl alcohol with 99.7 wt.\% was about $3,003 \mathrm{~kg} / \mathrm{h}$ and the total steam consumption required for the process was about 4,761 $\mathrm{kg} / \mathrm{h}$. Overall, compared to the use of ethylene glycol, the use

TABLE-4

SIMULATION RESULTS OF 3 COLUMN CONFIGURATION WHEN EG OR DMSO IS USED AS AN EXTRACTION SOLVENT

\begin{tabular}{lcc}
\hline \multicolumn{1}{c}{ Items } & $\begin{array}{c}\text { Three-columns } \\
(\mathrm{EG})\end{array}$ & $\begin{array}{c}\text { Three-columns } \\
(\mathrm{DMSO})\end{array}$ \\
\hline Condenser duty of T01 $(\mathrm{kcal} / \mathrm{h})$ & $0.6446 \times 10^{6}$ & $0.6401 \times 10^{6}$ \\
Condenser duty of T02 $(\mathrm{kcal} / \mathrm{h})$ & $0.9655 \times 10^{6}$ & $0.9655 \times 10^{6}$ \\
Condenser duty of T03 $(\mathrm{kcal} / \mathrm{h})$ & $0.5735 \times 10^{6}$ & $0.5466 \times 10^{6}$ \\
Total condenser duty $(\mathrm{kcal} / \mathrm{h})$ & $2.1476 \times 10^{6}$ & $2.1522 \times 10^{6}$ \\
Reboiler duty of T01 $(\mathrm{kcal} / \mathrm{h})$ & $0.6537 \times 10^{6}$ & $0.6492 \times 10^{6}$ \\
Reboiler duty of T02 $(\mathrm{kcal} / \mathrm{h})$ & $1.3092 \times 10^{6}$ & $1.1671 \times 10^{6}$ \\
Reboiler duty of T03 $(\mathrm{kcal} / \mathrm{h})$ & $0.5019 \times 10^{6}$ & $0.5147 \times 10^{6}$ \\
Total reboiler duty $(\mathrm{kcal} / \mathrm{h})$ & $2.4648 \times 10^{6}$ & $2.3310 \times 10^{6}$ \\
Solvent circulation rate $(\mathrm{kg} / \mathrm{h})$ & 4,017 & 3,003 \\
C/W consumption $(\mathrm{ton} / \mathrm{h})$ & 268 & 269 \\
MP steam consumption $(\mathrm{kg} / \mathrm{h})$ & 5,035 & 4,761 \\
\hline T01: Concentrator, T02: Extractive distillation column. T03: Solvent \\
recovery column, C/W: Cooling water $\left(\right.$ supply temp, $32{ }^{\circ} \mathrm{C}$, discharge \\
temp. $\left.40{ }^{\circ} \mathrm{C}\right)$, MP steam: $180{ }^{\circ} \mathrm{C}$ saturated steam & \\
\hline
\end{tabular}

of DMSO as the extractive solvent for the refinement of isopropyl alcohol with 99.7 wt. \% purity reduced the solvent inflow rate by $25 \%$ and decreased the total steam consumption by $5.4 \%$.

Comparison of the energy consumption of the twocolumn distillation configuration and the three-column configuration using DMSO as the extractive solvent: Table5 shows a comparison of the energy consumption of the twocolumn distillation configuration and the three-column configuration when DMSO was used as the extractive solvent. Based on the results, the solvent inflow rate of DMSO for the acquisition of isopropyl alcohol with $99.7 \mathrm{wt}$.\% purity in the twocolumn distillation configuration was $4,397 \mathrm{~kg} / \mathrm{h}$ and the total steam consumption required for this process was about 7,131 $\mathrm{kg} / \mathrm{h}$. In comparison, the solvent inflow rate of DMSO for the recovery of isopropyl alcohol with $99.7 \mathrm{wt} \%$ purity in the three-column distillation configuration was $3,003 \mathrm{~kg} / \mathrm{h}$ and the total steam consumption required for this process was about $4,761 \mathrm{~kg} / \mathrm{h}$. Overall, compared to the two-column configuration, the use of the three-column configuration reduced the solvent inflow rate of DMSO by $31.7 \%$ and the total steam consumption by $33.2 \%$.

TABLE-5

COMPARISON BETWEEN 2 COLUMN CONFIGURATION AND 3 COLUMN CONFIGURATION USING DMSO AS AN EXTRACTION SOLVENT

\begin{tabular}{lcc}
\hline \multicolumn{1}{c}{ Items } & $\begin{array}{c}\text { Two-columns } \\
\text { (DMSO) }\end{array}$ & $\begin{array}{c}\text { Three-columns } \\
(\mathrm{DMSO})\end{array}$ \\
\hline Condenser duty of T01 $(\mathrm{kcal} / \mathrm{h})$ & - & $0.6401 \times 10^{6}$ \\
Condenser duty of T02 $(\mathrm{kcal} / \mathrm{h})$ & $0.9655 \times 10^{6}$ & $0.9655 \times 10^{6}$ \\
Condenser duty of T03 $(\mathrm{kcal} / \mathrm{h})$ & $2.2018 \times 10^{6}$ & $0.5466 \times 10^{6}$ \\
Total condenser duty $(\mathrm{kcal} / \mathrm{h})$ & $3.1673 \times 10^{6}$ & $2.1522 \times 10^{6}$ \\
Reboiler duty of T01 $(\mathrm{kcal} / \mathrm{h})$ & - & $0.6492 \times 10^{6}$ \\
Reboiler duty of T02 $(\mathrm{kcal} / \mathrm{h})$ & $1.3303 \times 10^{6}$ & $1.1671 \times 10^{6}$ \\
Reboiler duty of T03 $(\mathrm{kcal} / \mathrm{h})$ & $2.1020 \times 10^{6}$ & $0.5147 \times 10^{6}$ \\
Total reboiler duty $(\mathrm{kcal} / \mathrm{h})$ & $3.4323 \times 10^{6}$ & $2.3310 \times 10^{6}$ \\
Solvent circulation $\mathrm{rate}(\mathrm{kg} / \mathrm{h})$ & 4,397 & 3,003 \\
C/W consumption $($ ton $/ \mathrm{h})$ & 396 & 269 \\
MP steam consumption $(\mathrm{kg} / \mathrm{h})$ & 7,131 & 4,761 \\
\hline T01: Concentrator, T02: Extractive distillation column. T03: Solvent \\
recovery column, C/W: Cooling water (supply temp, 32 ${ }^{\circ} \mathrm{C}$, discharge \\
temp. $\left.40^{\circ} \mathrm{C}\right), \mathrm{MP}$ steam: $180{ }^{\circ} \mathrm{C}$ saturated steam
\end{tabular}

Two-column configuration distillation column was compared with the three-column configuration distillation column for the process of producing high purity (99.7 wt.\%) isopropyl alcohol from recycled isopropyl alcohol wastewater in which the temperature, pressure, inflow rate and compositions are shown in Table-2. In addition, the solvent ability of ethylene glycol and DMSO was also compared. The results of this comparison are as follows:

(1) The use of DMSO as the extractive solvent for the refinement of 99.7 wt.\% isopropyl alcohol can reduce the solvent inflow rate by $25-35 \%$ and the total steam consumption by $5.4-5.8 \%$ relative to the use of ethylene glycol. Thus, DMSO is more effective as the extractive solvent for the refinement of isopropyl alcohol than ethylene glycol.

(2) A minimum total reboiler heat duty of $2.4648 \times 10^{6}$ $\mathrm{kcal} / \mathrm{h}$ was achieved using the three-column configuration when ethylene glycol was used as the extractive solvent and 
the isopropyl alcohol purity reached $84.5 \mathrm{wt} . \%$ on the upper part of the concentrator. Furthermore, when DMSO was used as the extractive solvent and the isopropyl alcohol purity reached 84.4 wt.\%, the total reboiler heat duty reached its minimum at $2.3310 \times 10^{6} \mathrm{kcal} / \mathrm{h}$.

(3) Compared with the use of the two-column configuration, the three-column configuration effectively reduced the inflow rate of the extractive solvent (DMSO) by $31.7 \%$ and decreased the total steam consumption by $33.2 \%$. Thus, the use of DMSO as the extractive solvent is more advantageous than the use of ethylene glycol with respect to the process size and energy consumption.

\section{Symbols}

$\begin{array}{ll}\mathrm{T} & : \text { Absolute temperature }[\mathrm{K}] \\ \gamma_{\mathrm{i}} & : \text { Activity coefficient of component } \mathrm{i} \\ \chi_{\mathrm{j}}, \chi_{\mathrm{k}} & : \text { Liquid mole fraction of component } \mathrm{j} \\ & \text { and } \mathrm{k} \\ \mathrm{a}_{\mathrm{ij}}, \mathrm{a}_{\mathrm{ji}}, \mathrm{b}_{\mathrm{ij}}, \mathrm{b}_{\mathrm{ji}}, \alpha_{\mathrm{ij}}: & \text { Binary interaction parameter in NRTL } \\ & \text { mixing rule } \\ \delta & : \text { Reduced mixture density } \\ \mathrm{T} & : \text { Inverse reduced mixture temperature }\end{array}$

\section{ACKNOWLEDGEMENTS}

This research was supported by a grant from LNG Plant R\&D Center founded by Ministry of Land, Transportation and Maritime affairs (MLTM) of the Korean government.

\section{REFERENCES}

1. M. Yorizane, S. Yoshimura and T. Yamamoto, Kagaku Kogaku, 31, 451 (1967).

2. H. Renon and J.M. Prausnitz, AIChE J., 14, 135 (1968).

3. D.S. Abrams and J.M. Prausnitz, AIChE J., 21, 116 (1975).

4. G.M. Wilson, J. Am. Chem. Soc., 86, 127 (1964).

5. D.Y. Peng and D.B. Robinson, Ind. Eng. Chem. Fundam., 15, 59 (1976).

6. G. Soave, Chem. Eng. Sci., 27, 1197 (1972).

7. F. Liu, F. Huang and C. Zhang, Chem. Technol., 19, 254 (1993).

8. Yu.V. Golubkov, N.V. Kotenkova and A.N. Shapovalova, Zh. Prikl. Khim., 55, 1170 (1982).

9. M. Nishimura, M. Nakayama and T. Yano, J. Chem. Eng. Jpn., 5, 223 (1972).

10. N.M. Sokolov, L.N. Tsygankova and N.M. Zhavoronkov, Khim. Tekhnol., 5, 900 (1971). 